\title{
La mirada sartriana: poder y otredad en L'Être et le Néant, La Nausée y Huis clos ${ }^{1}$
}

\section{(The Sartrean View: Power and Otherness in L'Être et le Néant, LaNausée and Huisclos)}

\author{
Andrew Lloyd Smith ${ }^{2}$
}

Universidad Nacional, Costa Rica

\section{resumen}

En L'Etre et le Néant y La Nausée, Jean-Paul Sartre le otorga importancia a la mirada: aspecto esencial para explorar el tema existencial. Así, se analizan interrogantes y reflexiones como las siguientes: sin la mirada del otro, ¿cómo puedo saber verdaderamente que existo? Al verme y confirmar mi existencia, en ese mismo instante, la otra persona me convierte en un objeto, pues el observador es el sujeto de su mirada. Al mirar a los demás, soy también sujeto de mi mirada y convierto a los otros en objeto. El juego de la mirada es un juego de poder. La obra de teatro Huis clos también presenta el juego sartriano de poder y mirada, que será analizado en esta ponencia.

\section{résumé}

Dans ses libres L'Être et le Néant et La Nausée Jean-Paul Sartre donne beaucoup d'importance au « regard». Sartre nous dit que le regard est un aspect essentiel pour explorer le thème existentiel. Des questions et des réflexions comme les suivantes seront étudiées : sans le regard d'une autre personne, comment puis-je savoir si j'existe vraiment ? Quand une personne me regarde, elle confirme mon existence, mais en même temps elle me convertit en un objet puisque la personne qui me regarde est le sujet de son regard. Moi, quand je regarde l'autre personne je suis aussi le sujet de mon regard et je convertis l'autre personne en un objet. Ce jeu du regard est un

1 Recibido: 7 de mayo de 2014; aceptado: 22 de junio de 2014.

2 Escuela de Literatura y Ciencias del Lenguaje. Correo electrónico: asmith@ice.co.cr

$$
L_{\text {etras }} 55 \text { (2014), ISSN 1409-424X; eISSN 2215-4094 }
$$


jeu du pouvoir. La pièce de théâtre de Sartre Huis clos aussi présente ce jeu sartrien du pouvoir et du regard et sera analysée dans cette communication.

Palabras clave: la mirada, Jean-Paul Sartre, el objeto, el sujeto, la existencia, el poder.

Mots-clés : le regard, Jean-Paul Sartre, l'objet, le sujet, l'existence, le pouvoir

Recuerdo que de niño se me ocurrió que tal vez mi percepción del mundo era completamente diferente a la de los otros y que posiblemente la forma en que percibía el color verde o a un pájaro podía ser errónea y mi verde, en realidad, podía ser otro color y el pájaro era más bien un gato o algo distinto para el resto de la humanidad. Tal vez, los demás me veían a mí y al mundo de una forma diferente a mis propias percepciones. Recuerdo que pensaba que no había forma de probar si mi idea era falsa o verdadera, pues nunca podría ver el mundo a través de los ojos de otra persona. Su percepción del color verde o del pájaro era en realidad irrelevante, pues era la percepción de ellos y no la mía. También me acuerdo cuando un amigo me dijo que si un árbol cae en el bosque y no hay nadie para oírlo, no hay sonido percibido por la caída, ya que no había oídos para capturar ese sonido. Luego pasé horas tratando de entender lo que era real y lo que no era real y no encontré respuesta.

También recuerdo que pensé que si mi madre sabía que yo estaba pensando estas cosas, ella me diría que dejara de perder mi tiempo en tontos pensamientos y probablemente me daría algún trabajo para realizar, para así asegurarse de que yo parara de soñar despierto o divagar. Muy poco sabía, en aquel entonces, que yo estaba filosofando. Recuerdo la primera vez que leí la frase de Descartes: «Pienso luego soy». Después de considerarla por un tiempo, llegué a la conclusión, así como todo el mundo, de que esa aseveración no era discutible. Si podía pensar, entonces tenía que existir porque estaba pensando. 
En El ser y la nada ${ }^{3}$, Jean-Paul Sartre escribe sobre este tipo de temas o interrogantes. Al hacerlo, el filósofo francés le otorga mucha importancia a la idea de «la mirada». Cuando pensamos en la idea de nuestra existencia, Sartre nos dice que la mirada es un aspecto esencial. Si yo no soy visto o percibido por alguien, el otro, ¿cómo puedo estar seguro de que yo existo? Cuando veo a otra persona, estoy seguro de que el individuo existe, pero él o ella no me ve, ¿eso no causa en mí una duda existencial? Yo puedo pensar que estoy aquí, pero sin nadie para corroborarlo, ¿cómo puedo estar seguro? Sin embargo, Descartes dice que el pensamiento es suficiente para probar que estoy aquí. Aunque Sartre podría contestarle: «Sí, ¿pero en qué forma?». Descartes prueba la existencia de Dios, mediante la idea de «duda como certeza» y luego «prueba» que todos tenemos un alma ${ }^{4}$.

Sartre es más escéptico que Descartes, y nos dice que todos somos solamente como nos perciben los otros. La mirada del otro sobre mí le muestra a esta persona que hay un ser que existe. Sin embargo, Sartre también dice que mi solo ser, es decir mi cuerpo, puede ser percibido por esta mirada y que mi conciencia, mi alma, no puedo ser percibida por los ojos, y por lo tanto, no puede considerarse como existente. Yo solo soy lo que es visto por la mirada de los otros.

Este otro, al mirarme, básicamente me convierte en un objeto. Según Sartre, todos somos sujetos y objetos. Yo soy el sujeto cuando pienso sobre mí mismo. Yo no puedo convertirme en un objeto, es decir, alguien quien está siendo visto, ya que mi autopercepción de mi mismo viene de mí. Yo soy el sujeto de mí mismo. Incluso, si yo me miro a mí mismo en un espejo, yo lo sé, pues estoy consciente de este hecho. Entonces, yo continúo siendo un sujeto, esto es, la persona que está pensando, pero también soy objeto cuando me veo, pues en el espejo soy sujeto y objeto. Sin embargo, cuando soy visto por el otro, yo me vuelvo un objeto de su mirada.

3 Jean-Paul Sartre, El ser y la nada. Trad. Juan Valmar (Buenos Aires: Losada, 1975).

4 Ver André Lagarde y Laurent Michard, XVIIe siècle. Collection littéraire Lagarde \& Michard (París: Bordas, 1970) 86; René Descartes, Le Discours de la méthode (París: Bordas, 1965) 102. 
La mirada del otro se apodera del mundo o de la realidad, que considero mía y me quita. Puesto que soy mirado y percibido por otra persona, ya no soy el centro de mi propio universo. Mi realidad está compartida con la otra persona, quien me está contemplando. Soy ahora un objeto para la otra persona y mi subjetividad ha sido tomada por la mirada del Otro. Eso es lo que parece pasar al narrador de «The Tell-Tale Heart», de Edgar Allan Poe, cuando es mirado por el ojo azul pálido de un hombre viejo. Este escrutinio lo enloqueció e hizo que asesinara al anciano con tal de deshacerse de su mirada, aún cuando decía amar al viejo ${ }^{5}$.

El poder de la mirada del otro sobre mí es substancial y básicamente, me controla, define y asegura mi existencia. Sartre usa el ejemplo del acto vergonzoso para ilustrar su concepción de existencia humana. El filósofo dice que cuando se comete un acto vergonzoso, por ejemplo, mirar a través de la cerradura de una puerta, la persona está consciente del acto que está cometiendo y de nada más. La persona deja de existir, solo existe el acto, la persona es el acto. Según Sartre, este acto vergonzoso no es culpa de nadie, la situación simplemente existe. Sin embargo, todo cambia si yo soy atrapado cometiendo ese acto vergonzoso. La mirada del Otro sobre mí cuando cometo ese acto, de pronto me devuelve la existencia. Yo soy visto, yo existo, y más importante, yo soy juzgado. De pronto, yo soy culpable y siento vergüenza. Esta vergüenza procede de la percepción que el Otro tiene de mí, él o ella me juzga. De la misma forma, yo solo puedo sentir orgullo si estoy siendo positivamente juzgado por otra persona. En suma, Sartre dice que sin la mirada, nosotros no podemos estar seguros de nuestra existencia; necesitamos la mirada del Otro para saber que existimos.

Sin embargo, aun si la mirada del Otro es importante en nuestra vida, no podemos depender de esta para justificar nuestra existencia. En La Nausée, Sartre dice lo siguiente: «jamais un existant ne peut

5 George McMichael (ed.), Anthology of American Literature (Nueva York: Macmillan, 1985) 961. 
justifier l'existence d'un autre existant» [«jamás un ser existente puede justificar la existencia de otro ser existente» $]^{6}$.

El intelecto de Sartre, es decir, su habilidad de escribir, su poder de persuasión hacen que sus argumentos parezcan posibles, pero en realidad uno podría discutir sus teorías, especialmente, la importancia dada a la mirada. ¿No es simple inseguridad mantener que mi propia existencia depende de la mirada de otro individuo? Una persona segura sabe que existe, con la presencia de la mirada de otro o sin ella. Una persona segura no deja que la mirada de otra persona determine su existencia.

La idea de Sartre de que nuestro ser es lo que perciben los otros, es decir, sin conciencia separada o alma, o como decidamos llamar a la parte de nosotros que nos hace pensar, es algo debatible. Solo porque no podamos ver nuestra alma, nuestro espíritu ni nuestra conciencia, esto no significa necesariamente que esta esté pegada a nuestro cuerpo y que fallece cuando nuestro cuerpo muere. Para ilustrar esta inquietud, uno podría acudir a casos de personas clínicamente muertas, que luego reviven, como un argumento de que nuestra conciencia o una parte de nuestro ser continúa existiendo después de nuestra muerte. Tan controversial como esto es, uno podría también usar la idea de los sueños, y las experiencias extra-corporales como los desdoblamientos e incluso la idea de los fantasmas como un tipo de señal de que nuestra existencia puede no solo ser asociada con nuestro cuerpo y que nosotros, como Descartes afirma, tenemos un alma o una parte de nosotros que continúa existiendo después de que nuestro cuerpo ha muerto.

De la misma forma, la idea de Sartre de que la vergüenza o el orgullo existen solamente porque los otros nos juzgan es también debatible. Por lo general, cuando se hace algo realmente vergonzoso, nosotros sabemos que estamos haciendo algo vergonzoso. Adiferencia de lo sostenido por Sartre, no llegamos a convertirnos en el acto ni 
perdemos la conciencia respecto de lo que estamos haciendo. No hace falta que alguien me atrape en un acto vergonzoso para que yo me dé cuenta que es un acto vergonzoso. Una persona razonablemente «normal» sabe cuándo un acto es vergonzoso. De la misma forma, si una persona actúa con caridad, con un acto de bondad, y nadie lo sabe excepto ella, puede sentirse orgullosa de esa acción, sin ser juzgada por los otros y sin hacerlo en busca de la aprobación de los demás o para obtener alabanzas. Una persona segura de sí misma no necesita confiar solo en la percepción que otra persona tiene, para poder sentir vergüenza u orgullo.

Es fácil ser seducido por el intelecto de Sartre y por sus interesantes teorías, pero al mismo tiempo, se puede también señalar que estas teorías, entre ellas, la teoría de la mirada, no son necesariamente verdad o realidad, términos también cuestionados como lo puede ser el poder de la mirada sartriana en el proceso identitario desde la perspectiva de la Otredad.

La importancia que Sartre da a la mirada se percibe en su obra literaria. En La Nausée (La náusea), por ejemplo, el personaje principal de la novela, Antoine Roquentin, está en proceso de tener una crisis de conciencia; lo que Sartre llamaba «la prise de conscience» («la toma de conciencia»). Esto es cuando el individuo se da cuenta no solo de la realidad de su existencia, sino también, según Sartre, de lo absurdo de la existencia humana. Roquentin empieza a sentir náuseas cuando se pregunta acerca de su existencia: por qué existe y cuál es su papel en la vida, etc. En un pasaje del libro, Roquentin cae en lo que llama «la trampa del espejo» ${ }^{7}$. Cuando se mira en un espejo, sin querer, siente la necesidad, la obligación de contemplarse en el espejo. Pierde la conciencia acerca de su identidad y cree que su cara desaparece, que no queda «nada humano» y que su rostro no se asemeja a nada; sin embargo, paradójicamente, todo lo demás sigue siendo familiar. El personaje empieza a dormirse y toca su propia

7 Sartre, La Nausée, 32-33. 
mejilla cuando de golpe se despierta porque pierde el equilibrio y por poco cae. Roquentin dice que él quiere "entenderse" al ver su cara, pero no puede. Es como si no pudiera convertirse en objeto, como si estuviera buscándose como sujeto y como objeto al mismo tiempo: al menos está buscando algo en el espejo, algo que no encuentra.

La idea de la mirada es aun más importante y tiene un papel mucho más relevante en la obra de teatro titulada Huis clos (A puerta cerrada). En esta pieza dramática, la idea de la mirada domina casi toda el texto. La trama de la obra es simple: Garcin, un periodista, Inés, una empleada de correos, y Estelle, una mujer de alta sociedad, están encerrados en una sala de estilo Segundo Imperio por toda la eternidad. El salón es el infierno y la única tortura que va a sufrir cada uno de ellos es la presencia permanente de los otros dos personajes. La frase clave de la obra es: «l'enfer c'est les Autres» («el infierno es los Otros») ${ }^{8}$. Después de entrar en el infierno, los tres personajes empiezan a discutir y se hieren mutuamente, pues exigen la verdad, aunque nadie está dispuesto a pronunciarla. Todos prefieren mentir en el infierno como lo hicieron en el mundo.

Así, Garcin está en el infierno por haber desertado durante la guerra, presa del miedo; en suma, por haberse comportado como un cobarde. Este personaje entiende que se halla en el infierno, pero no quiere aceptar la verdadera razón de su condena; prefiere que alguien le digaque no esuncobarde. Inés estáen el infierno porquehabía sido cruel con los demás y había separado a una pareja, porque, como lesbiana, quería seducir a la mujer. Inés entiende por qué está en el infierno, pero su mala fe continúa incluso allí, puesto que quiere seducir a Estelle, que no es lesbiana ni la quiere. Estelle es el personaje que acepta con más dificultad su presencia en el infierno. Ella no quiere aceptar ni el hecho de que está en el infierno ni aceptar ninguna responsabilidad por su situación. Estelle dice que es un error y que no sabe por qué está allí con los otros. Cuando se habla de la muerte, ella no acepta

8 Jean Paul Sartre, Huis clos (París: Gallimard, 1947) 93. 
la palabra «muerto» y prefiere el término «ausente», como si un día pudiera volver a la Tierra. Ella quiere creer que los tres personajes pueden existir de modo armonioso en el infierno como si fuera un lugar normal. Estelle está en el infierno por haber matado a su hija recién nacida, entre otras razones. Los tres personajes se cuestionan y se «torturan» entre sí hasta que cada uno dice la verdad acerca del por qué está en el infierno; entonces, la tortura sigue para siempre.

Además de la tortura psicológica y la búsqueda de la verdad, en esta obra, se ve la importancia dada a la mirada de tres maneras diferentes. La primera es cuando los personajes hablan del espejo o buscan un espejo. La segunda manera es cuando los personajes hablan directamente acerca de la mirada de ellos mismos o de la mirada de los otros, ya sea en el infierno o en la Tierra. La tercera manera se da cuando Sartre se refiere a ella en la obra, pero sin mencionarla de manera expresa, sino mediante juegos de palabras o a través del léxico que utiliza.

Como se señaló antes en este ensayo, la imagen del espejo es relevante, porque permite a un individuo verse como objeto, siendo sujeto. Esto quiere decir que la persona tiene la impresión de mantener el control de una situación o de sí mismo. No obstante, ya que la imagen del espejo no es real -es solo un reflejo -, tal vez todo es solo una ilusión. En La náusea, Roquentin no logra entender su imagen en elespejo y se pierde viéndola. En A puerta cerrada, no hay verdaderos espejos, solamente se nota la ausencia de estos. Acto seguido, esta ausencia entra en juego en la obra. El primer personaje que llega al infierno, Garcin, es acompañado por el Mozo, un personaje ambiguo que trabaja en el lugar y bien puede ser el diablo, un demonio o un ángel. Garcin le pregunta acerca de los instrumentos de tortura; el Mozo contesta que no los hay. Garcin observa que además, no hay espejos, ventanas ni nada frágilen el salón ${ }^{9}$. Es interesante que el primer objeto que Garcin busque después de saber que no hay instrumentos

9 Sartre, Huis clos, 15. 
de tortura es algo donde él pueda verse, un espejo. Garcin sabe que está muerto, pero es como si quisiera reafirmar su existencia.

Algunos renglones más adelante, en la escenaIII, Inés, la segunda en llegar, entra en el infierno y traba contacto con Garcin, quien le advierte: «Eh bien la glace est rompue». Esta frase ofrece el primer juego de palabras con el término «espejo». En francés, «glace» significa «hielo»y «espejo». Garcin asevera: «Ya se ha roto el hielo», pues ha iniciado la conversación, pero también el enunciado implica que «Ya se ha roto el espejo». Sartre, a través de Garcin, está jugando con las palabras, pero también Garcin, de una manera inconsciente, está diciéndole a Inés que no hay espejo, es decir, que su propia identidad no existe, solo la identidad que él, como sujeto portador de la mirada, va a darle a ella, convirtiéndola en objeto.

Inés cree que Garcin es el verdugo, porque según ella, los verdugos parecen tener miedo. Garcin le pregunta: «¿Y de quién? ¿De sus víctimas? $\gg^{10}$. Inés contesta que sabe lo que dice, porque ella se ha mirado en el espejo. Garcin responde: « ¿En el espejo?... Es fastidioso: aquí han quitado todo lo que pudiera parecerse a un espejo» ${ }^{11}$. Al analizar este intercambio de significados, podemos ver que justo antes de entrar en el salón (el infierno), Inés admite haberse mirado en un espejo. Esto implica que los condenados disponen de un espejo para contemplarse por última vez antes de entrar en el infierno. Desde luego, parece temer, porque reconoce esta misma emoción en la cara de Garcin. Inés va a ser el verdugo de Garcin (y más tarde, de Estelle) y ella asume que Garcin, con el mismo miedo y la misma mirada en su cara, es el verdugo verdadero. Garcin quiere ver un espejo otra vez para restablecer su propia identidad, pero de ahora en adelante, su identidad es lo que Inés (y Estelle) decidan que sea. En la escena IV, Inés dice a Garcin que no vale la pena mostrar su «hocico de verdugo» y otra vez él quiere un espejo: «Yo daría cualquiera cosa

10 Sartre, Huis clos, 24.

11 Sartre, Huis clos, 24-25. 
por mirarme en un espejo» ${ }^{12}$. En verdad, Garcin quiere volver a la certeza de mirarse, ver su cara en un espejo, para volver a afirmar su antigua existencia.

Estelle, una joven y bella mujer, habla más del espejo que los otros dos personajes; a causa de ello uno se puede preguntar: ¿es por vanidad o por inseguridad? Probablemente, ambas razones sirvan como respuesta. La mala fe de Estelle es más grande que la de los otros dos personajes. Ella es la última persona en entender y aceptar que está en el infierno y su necesidad de mirarse en un espejo para afirmar su existencia es muy fuerte. De las páginas 44 a 48 hay un pasaje interesante, en el que se ve la importancia que Estelle da al espejo. Ella pide un espejo a Garcin, quien no le contesta pues no quiere hablar con los otros, creyendo que así puede evitar la tortura. Inés, cuya mala fe en el infierno consiste en creer que puede seducir a Estelle, es quien le contesta. Inés tenía un espejo en su bolso antes de entrar al infierno, pero se lo quitaron cuando entró sin que lo supiera. Estelle, molesta por la falta de espejos, cierra los ojos y después de un rato casi se cae. Dice que se debe a que si ella no se ve, se pregunta si de verdad existe. Aquí vemos otra vez la necesidad de la mirada, nuestra propia mirada sobre nosotros mismos, para confirmar nuestra existencia. Después, Estelle habla de su antiguo cuarto, en donde ella tenía seis espejos grandes. Ella dice que puede visualizarlos ahora, pero que ellos no la ven a ella. Afirma que un espejo sin ella es una cosa vacía; luego, explica que al hablar, ella se ponía siempre en un lugar donde podía verse en uno de los espejos. Ella hablaba y se miraba mientras tanto; reconoce que veía como los otros la miraban y que aquello la mantenía despierta. Finalmente, Estelle manifiesta que no puede quedarse sin espejo por toda la eternidad.

Este interesante pasaje dice mucho de Estelle. Primero, mira los espejos y está esperando que le devuelvan su mirada, pero no lo hacen. Ella es sujeto, buscando un objeto, y como Garcin, quiere un

$\Gamma 2$ Sartre, Huis clos, 62. 
objeto controlado, ella misma quiere verse en un espejo. Ella también quiere reafirmar su existencia, pero como Garcin e Inés, no va a poder porque ya no existe. Es interesante que Estelle se mirara mientras hablaba. Así, ella tenía la ilusión de controlar no solamente su imagen, sino sus palabras también. Si se miraba en el espejo mientras hablaba, podía creer que su imagen y palabras eran controladas por ella, que su mirada tutelaba ambas cosas al mismo tiempo. Tal ilusión es completa, pues en su mente tiene poder total sobre su reflexión y todo lo que ella refleja.

En El flaneur en las prácticas culturales, el costumbrismo y el modernismo, Dorde Cuvardic afirma que el juego de la mirada es, a menudo, un juego de seducción o un juego de placer, es decir, un juego practicado por los miembros de la sociedad ${ }^{13}$. Aunque a Inès le gustaría jugar el «juego de la mirada como seducción» con Estelle, el juego que en realidad juega en A puerta cerrada es completamente diferente. En el pasaje supracitado, se ve cómo Inés, consciente de su condición de condenada sin esperanza en el infierno, demuestra mala fe en su incapacidad de entender que no puede tener a Estelle. En la escena, Estelle pide el espejo a Garcin, quien no le contesta. Inés pregunta a Estelle si ella quiere que le sirva de espejo, usando sus propios ojos. Sartre mezcla en este pasaje la imagen de los ojos y la del espejo. Estelle no se ve bien en este nuevo «espejo», porque es demasiado pequeña, dice ella. Esto es lo que Inés quiere. Así, ella puede controlar la imagen de Estelle. La idea de sujeto y objeto es relevante aquí, pues ¿quién ve a quién?, ¿quién es objeto y quién es sujeto? Inés debe ser sujeto porque está viendo solo a Estelle. Estelle se está viendo en los ojos de Inés, pero se está buscando a sí misma. Estelle parece ser sujeto, buscando otra vez su reflexión para reconfirmar su existencia, pero no la ve, y no ve a Inés tampoco, entonces es un objeto. Inés, quien cumple el papel de espejo u objeto de reflexión, es en realidad un sujeto viendo a Estelle. Y Estelle no está contenta

13 Dorde Cuvardic García, El flaneur en las prácticas culturales, el costumbrismo y el modernismo (París: Publibook, 2012) 190, 209. 

con este espejo controlador. Inés le pregunta si ella no vale más que un espejo y Estelle le contesta que Inés le intimida y que su imagen en los espejos estaba «domesticada». Ante la pregunta ¿cómo se puede domesticar una mirada en un espejo?, no hay una respuesta posible y la reflexión que se ve es lo que Estelle quiere ver, no lo que se refleja de verdad. Ella imagina otra reflexión, distorsiona la reflexión que ve en el espejo. Ahora, en el infierno, donde no se puede mentir ni cambiar las cosas que uno quiere cambiar, Estelle está totalmente intimidada por la situación.

Además de la imagen de los ojos como espejo, también se incluyen referencias directas acerca de los ojos en A puerta cerrada. Sartre afirma en El ser y la nada que el ojo no es la mirada misma, sino el apoyo de la mirada. En A puerta cerrada esta idea de apoyo se identifica con claridad. Desde el principio de la obra, cuando Garcin entra en el infierno, Sartre empieza a demostrar la importancia del ojo. Garcin pregunta al Mozo si se duerme en este lugar y el Mozo le contesta que no. Luego, al pensar en esto, Garcin se da cuenta de que el Mozo no parpadea. Entonces, Garcin da una explicación detallada de la importancia de poder cerrar los ojos para dejar de ver, aunque sea por un instante ${ }^{14}$. Ahora bien, en el infierno, Garcin no solo no va a poder dormir, sino que tampoco va a soñar ni poder cerrar los ojos. Figurativamente, cuando Garcin podía cerrar los ojos en la Tierra, él podía escaparse un rato de la realidad, de la verdad; podía no ser ni el sujeto ni el objeto de los otros. Ahora, muerto en el infierno, no puede escapar; está obligado a ver y a entender todo, sobre sí mismo y acerca de los otros dos personajes. Como él mismo dice: «Hay que vivir con los ojos abiertos» ${ }^{15}$. Esto parece ser demasiado para Garcin, pues al decirlo, oculta el rostro con sus manos. En este momento, entra Estelle, quien no quiere ver la cara de Garcin, pues cree que se trata de su amante fallecido, quien se había suicidado y reunía con ella en el infierno. Garcin no quiere ver a nadie, pero Estelle entra y

14 Sartre, Huis clos, 17-18.

15 Sartre, Huis clos, 19. 
le obliga a ser un objeto otra vez. El deseo de Garcin, de esconderse de la «realidad» es imposible, y ahora que los tres personajes están juntos, no van a poder escaparse de la mirada de los otros.

Garry Leonard, en Imagined Gaze and Fictional Construction muestra cómo la ausencia de la mirada es a menudo intolerable. Un ejemplo está en el filme Psycho, de Hitchcock; una secuencia en que Norman Bates no puede vivir sin la mirada de su madre, aunque fue él mismo quien la mató ${ }^{16}$. En A puerta cerrada, los tres personajes expresan frecuentemente la necesidad de mirarse unos a otros también. Como no hay espejos en el infierno, es imposible que ellos puedan afirmar su identidad y existencia, pero si son el objeto de la mirada del Otro, por lo menos, comprenden que todavía existen para otra persona. Inés se enoja cuando Garcin dice que quiere olvidarse de la presencia de los otros dos personajes. Es imposible, porque es precisamente la presencia de los otros lo que constituye el infierno. Inés quiere ser objeto de la mirada de Estelle, pero Estelle prefiere ver a Garcin. Inés confiesa a Garcin que ella no puede escapar de la existencia de los otros dos y que Garcin le ha robado la cara. Él la ve, pero Inés no se puede ver. Garcin, de nuevo, quiere esconder la cara con sus propias manos, pero Inés no lo permite. Ella le pide que se quite las manos de la cara, porque quiere escoger su propio infierno, es decir, que quiere mirar a los otros dos y luchar a «cara descubierta». Inés tiene miedo de perder su identidad, y exactamente como Garcin y Estelle, todavía no entiende que ya la ha perdido. Si Estelle no quiere mirarla, exige a Garcin que la mire. Una vez más demuestra su mala fe, pues aunque comprende que está en el infierno, sigue creyendo que tiene poder para controlar la situación, pero no lo tiene. Ella no puede escoger su propio infierno: ya ha sido escogido para ella. El hecho de querer mirar a los otros dos y luchar a «cara descubierta» demuestra que, a diferencia de Garcin, no quiere escapar de esta realidad.

16 Peter Vorderer y otros (ed.), Suspense: Conceptualization, Theoretical Analyses, and Empirical Explorations (Nueva York: Routledge, 1996) 27. 
Estelle también necesita la mirada de los Otros. En la Tierra, siendo una mujer joven y sensual, estaba acostumbrada no solo a su propia mirada reflejada en los espejos, sino a las miradas de los demás. El problema es que no quiere la mirada que está disponible, la de Inés. Estelle quiere la mirada de Garcin y le pide dos veces que la mire. Garcin también procura atraer la mirada de Inés, porque si Inés lo ve y le dice que no es cobarde, cree que esto será suficiente para no serlo. Garcin también busca la mirada de Estelle por la misma razón. Garcin cree que si alguien en el infierno le dice que no es un cobarde, no sería cobarde ni en el infierno ni en la Tierra, pues sus amigos están hablando acerca de él en la Tierra, lo juzgan.

En El ser y la nada, Sartre dice que cuando uno está mirando al otro, está juzgándolo. Garcin está muerto y sus «amigos» no lo pueden ver, pero él, como sujeto, puede verlos como objetos en la Tierra, que murmurabn acerca de él. Estos objetos de su mirada son, en realidad, sujetos en la Tierra, que hablan de él, el objeto, y lo describen como un cobarde. Garcin necesita sentirse objeto de un sujeto diferente, y por eso pide a Estelle que lo mire. Garcin afirma que él necesita que alguien lo mire mientras hablan de él en la Tierra. Garcin quiere cambiarse como sujeto; prefiere cualquier cosa que venga de Estelle que afrontar la verdad.

Sartre también se refiere indirectamente a la imagen de la mirada y eso se ve a menudo en los juegos de palabras o en el vocabulario del texto. Garcin dice a Estelle: «Il paraît que tu me faisais de l'œil» ${ }^{17}$, lo que se traduce literalmente como: «Pareciera que me hacías del ojo», y que quiere decir: «Parece que no me dejas de mirar». En consecuencia, Garcin cree que Estelle se interesa en él y lo expresa mediante la imagen del ojo.

Cuando Inés le expresa a Estelle un interés por ella, también utiliza la imagen de la mirada. Le dice que no tenga miedo, que ella la mirará sin parar y sin un parpadeo y que ella vivirá en su mirada

17 Sartre, Huis clos, 51. 
y encontrará lo que desea en el fondo de sus ojos. Estelle le pide a Inés que la deje, y asevera que Inés no tiene ojos. Para Estelle, el que Inés no tenga ojos supone que ella misma no se convertirá en objeto, pues nadie la va a ver. Más tarde, Garcin le dice a Estelle que ella le disgusta, y que se vaya porque él no quiere verla más; de nuevo, se utiliza el vocabulario de la mirada en el texto: «iVa-t'en! ...Je ne veux pas m'enliser dans tes yeux», que quiere decir: «Déjame!... Yo no quiero estancarme (hundirme) en tus ojos». El verbo francés «s'enlier» equivale a «hundirse». Si Estelle mira a Garcin, Garcin será el objeto y Estelle será el sujeto, así Garcin se pierde en esa mirada y por lo tanto, pierde su identidad. Esto parece contradecir muchas teorías literarias de la mirada. A menudo, es una fuerte mirada masculina la que mira a una mujer y el hombre es así quien controla la situación. Mulvey dice que el personaje masculino es normalmente el sujeto, convirtiendo a la mujer en un objeto ${ }^{18}$. Sin embargo, en To the Lighthouse, de Virginia Woolf, nosotros en realidad vemos, así como Estelle, una mirada femenina penetrante de parte de Mrs. Ramsay, que es «capaz de cambiar acciones y transformar jerarquías» ${ }^{19}$.

Finalmente, Garcin y Estelle van a hacer el amor en frente de Inés, por venganza, o simplemente para hacerla sufrir, pero Garcin no puede hacerlo sabiendo que Inés los está mirando, e Inés les promete que ella nunca les quitará los ojos de encima. Garcin no puede, mientras es objeto de la mirada de Inés, tomar como objeto a Estelle para amarla.

Al final de la obra, las visiones o «miradas» de la Tierra han desaparecido, nadie en el mundo piensa en ellos; es entonces, cuando los personajes se transforman en objetos y solo existen por ellos mismos; esta clase de existencia implica la tortura permanente. La obra termina con los tres personajes que se miran y ríen de horror; en el desenlace, Garcin propone: «Bueno, sigamos».

18 Kari Meyers y GiIda Pacheco, Women and/in Literature Unique Voices, Shared Visions (San José, Costa Rica: Editorial de la Universidad de Costa Rica, 2011) 129.

19 Meyers y Pacheco, 106. 
En conclusión, podemos ver cómo Jean-Paul Sartre, tanto en sus preceptos teóricos, presentes, por ejemplo, en L'Être et le Néant (El ser y la nada), como en sus obras literarias, particularmente en Huis clos (A puerta cerrada), otorga un papel preponderante a la mirada. Para Sartre, la mirada es esencial para nuestra propia existencia, pero el filósofo francés aclara que se trata de la mirada del otro, al menos así lo hace en el escrito teórico. En los textos literarios, esta posición exhibe una variante porque a través de la imagen del espejo, es mi propia mirada la que reafirma mi existencia; aunque mi propiareflexión podría jugar el papel del otro. Ya dijo Lacan, respecto del estadio del espejo, que todo yo es un otro ${ }^{20}$. Además, el binarismo de Sujeto/Objeto es también un tema que se destaca. El otro y yo podemos mirarnos mutua y simultáneamente y así, ambos somos sujetos y objetos a la vez. Así se muestra un sentido bastante posestructural, según el cual los dos entes son dinámicos e intercambiables.

Sin embargo, el poder de la mirada y el de la Otredad quedan muy bien plasmados y mejor visualizados en A puerta cerrada. En esta obra, no se da la doble vía del sujeto/objeto, es decir, el ser y el otro, sino se presenta la estructura de un triángulo, en que el yo siempre está con otros. Aunque los tres personajes se turnan para posesionarse de su subjetividad, siempre hay dos en contra de uno: siempre el poder de dos miradas de Otredad aniquila al sujeto. Sartre ha modificado la frase de Descartes; su versión, en lugar del «Pienso luego soy», dice: «Me miran, luego existo». Pero ya sea en el mundo con los postulados teóricos o en el infierno de un texto literario, siempre yo seré juzgado por otros. En todo caso, para ser sujeto, necesito del otro o de los otros, pues necesito objetos, miradas que reafirmen mi identidad y que atenúen lo absurdo de mi existencia, pues el ser y el otro pueden resultar el ser y la nada, ya sea abiertamente o a puerta cerrada.

20 Jacques Lacan, «The Mirror Stage as Formative of the Function of the I as Revealed in Psychoanalytic Experience», Vincent B. Leitch y otros (ed.), The Norton Anthology of Theory and Criti-

19 Sartre, Huis clos, 51 . W.W. Norton \& Company, 2001) 1285-1290. 